Received 15 May: accepted 2 August 1991.

1. Klymkowsky, M. W., Bachant, J. B. \& Domingo, A. Cell Motil. Cytoskel. 14, 309-331 (1989).

2. Lin, J. J. C. \& Feramisco, J. R. Cell 24, 185-193 (1981)

3. Gawlitta. W., Osborn, M. \& Weber, K. Eur. J. Cell Biol. 26, 83-90 (1981).

4. Klymkowsky, M. W. Nature 291, 249-251 (1981).

5. Tölle, H. G. Weber, K. \& Osborn, M. Exp/ Cell Res, 162, 462-474, (1986).

. Blose, S. H. Meltzer, D. I. \& Feramisco, J. R. J. Cell Biol. 98, 847-859 (1984)

7. Wehland, J. \& Willingham. M. C. J. Cell Biol. 97, 1476-1490 (1983).

Vale, R. D. A. Rev. Cell Biol. 3, 347-387 (1987)

8. Vale, R. D. A. Rev. Cell Biol. 3, 347-387 (1987).
9. Hollenbeck, P. J. \& Swanson, J. A. Nature 346, 864-866 (1990)

10. Rodonov. V. I., Gyoeva, F. K. \& Gelfand, V. I. Proc. natn. Acad. Sci. U.S. A. 88, 4956-4960 (1991).

1. Hollenbeck. P. J. 1. Cell Biol. 108, 2335-2342 (1989)

12. Stacey, D. W., Allfrey, V. G. \& Hanafusa, H. Proc. natn. Acad. Sci. U.S. A. 74, 1514-1618 (1977)

3. Hollenbeck, P. J., Bershadsky. A. D., Pletjushkina, O. Y., Tint, I. S. \& Vasiliev, J. M. J. Cell Sci. 92, 621-631 (1989)

14. Vale, R. D. \& Hotani, H. J. Cell Biol, 107, 2233-2241 (1988)

15. Dabora, S. L. \& Sheetz, M. P. Cell 54, 27-35 (1988).

16. Perides, G., Harter, C. \& Traub, P. J. biol. Chem. 262, 13742-13749 (1987).

17. Traub, P., Perides, G., Kühn, S. \& Scherbarth, A. Eur. J. Cell Biol. 43, 55-64 (1987)

18. Franke, W. W., Hergt, M. \& Grund, C. Cell 49, 131-141 (1987).

19. Katsumoto, T. Mitsushima, A. \& Kurimura. T. Biol Cell 68, 139-146 (1990).

20. Troyanovsky, S. M. et at. Immunologiya (USSR) 6, 70-73 (1985)

ACKNOWLEDGEMENTS. We thank L. S. B. Goldstein and M. de Cuevas for the HD plasmid and O. A. Deryabina for technical assistance.

\section{Cotranslocational insertion of apolipoprotein B into the inner leaflet of the endoplasmic reticulum}

\section{Richard J. Pease, Georgina B. Harrison \& James Scott}

Division of Molecular Medicine, MRC Clinical Research Centre, Watford Road, Harrow HA1 3UJ, UK

APOLIPOPROTEIN (apo) B100 is required for the distribution of hepatic triglyceride to peripheral tissues as very-low-density lipoproteins. The translocation of apo B100 into the endoplasmic reticulum (ER) and its subsequent assembly into lipoprotein particles is of particular interest as the protein is both very large (relative molecular mass 512,000) and insoluble in water. It has been proposed that apo $B$ translocation occurs in discrete stages and is completed post-translationally ${ }^{1}$. Several sites of arrest of translocation were reported to be present in apo $B 15$ (the $N$ terminal $15 \%$ of the protein). We have re-examined this question by in vitro translation coupled with translocation into microsomes, and find no evidence for transmembrane segments in truncated apo B proteins. Translocated apo B17 is strongly associated with the membrane of the $E R$, being only partially releasable with alkaline carbonate, and remaining bound to the microsomes following disruption with saponin. The efficient binding of short segments of apo $B$, despite the absence of transmembrane domains, suggests that apo $B$ is cotranslationally inserted into the inner leaflet of the ER. This will obviate problems caused by the size and insolubility of apo B100, because the growing hydrophobic protein chains will never exist in a lipid-free form during translocation. From the inner leaflet, apo $B$ in association with membrane-derived lipid can bud into the lumen of the ER to form nascent lipoprotein particles.

After biosynthesis apo B100 is either assembled into lipoprotein particles and secreted, or degraded intracellularly ${ }^{2,3}$. Studies of cells in culture indicate that a proportion of the molecules are untranslocated and destined for degradation and that the remainder are translocated and quantitatively secreted ${ }^{2}$. Studies of apo B15 translated in wheat-germ lysates have suggested that translocation pauses while translation continues, imposing transient transmembrane configurations ${ }^{1}$; we cannot confirm these observations.

To obtain efficient translation of apo B in reticulocyte lysates, a partial $5^{\prime}$ untranslated region (UTR) of mouse encephalomyocarditis virus (EMCV) (ref. 4) was fused to apo B complemen- tary DNA. The EMCV-apo B transcripts encode MetAla before the apo $B$ prepeptide sequence, but the extended signal still functions efficiently. Thus, apo $\mathrm{B} 7$ and $\mathrm{B} 9$ (Fig. $1 a, b$ ) increase in size after translation in the presence of microsomes owing to glycosylation ${ }^{5}$, and apo B9 is protected from trypsin digestion when translated with microsomes (Fig. $1 a$ ). When apo B7 is translocated in the presence of the competitive glycosylation inhibitor $N$-acetyl-AsnTyrThr-carboxyamide ${ }^{6}$, the principal product (unglycosylated apo B7) migrates faster than pre-apo B7, consistent with cleavage of the signal sequence (Fig. $1 b$ ). Cleavage $(\sim 90 \%)$ was confirmed by radiosequencing of processed apo B15 (results not shown).

In cultured cells apo B100 is carbonate-resistant ${ }^{7,8}$ immediately after biosynthesis, which indicates that integration into the ER membrane has taken place ${ }^{9}$. We therefore investigated whether the truncated apo B proteins bind to microsomes. Under conditions in which soluble secretory proteins are quantitatively released but a transmembrane protein will remain associated with the membrane, membrane binding was significant with proteins in the range apo B9 to B17, but less with apo B7 (Fig. $2 a$ ). Similarly, intermediate carbonate releasability has been found with apo $E$ in Golgi membranes ${ }^{8}$ : we have confirmed the membrane association of apo B17 following disruption with saponin (Fig. 2b).

Association of apo B with the ER membrane could either involve amphipathic binding to the inner leaflet, or the presence of transmembrane regions. We observed that after translation in reticulocyte lysates for either $40 \mathrm{~min}$ (when protein synthesis is ongoing) or for $90 \mathrm{~min}$ at $30^{\circ} \mathrm{C}$, both apo $\mathrm{B} 15$ and apo $\mathrm{B} 17$ are protected from trypsin or proteinase $\mathrm{K}$ (Fig. $3 a, b$; and data not shown), thereby excluding the presence of transmembrane domains. To ensure reproducible inactivation of proteinase $K$, it was necessary to centrifuge the membranes out of the digestion mixture, but this protocol precludes the controls of post-translational addition of microsomes or total disruption with detergent to verify proteinase $\mathrm{K}$ susceptibility of apo B17. Instead it was shown that apo B17 becomes susceptible to proteinase $\mathrm{K}$ after the membranes are permeabilized with saponin (Fig. 3b). Although we did not find transmembrane domains in apo B, we confirmed that $E_{1}$ glycoprotein is a transmembrane protein (Fig. $3 c)^{10}$

Finally we determined whether generation of transmembrane domains resulted specifically from wheat-germ ribosomes. Reduced expression of some transmembrane domains in reticulocyte lysates relative to wheat-germ lysates has been reported $^{11,12}$, although the topology of proteins expressed in mammalian cells is better predicted by translation in reticulocyte lysates $^{12}$. But we find no evidence for transmembrane domains when apo B15 is translated in wheat-germ lysates and the microsomes are digested with trypsin (results not shown) or proteinase $\mathrm{K}$ (Fig. $3 d$ ). Using densitometry to quantitate full-length chains after digestion we find (1) $71 \% \pm 13$ s.d. $(n=9)$ recovery of apo B17 in reticulocyte lysates with trypsin and (2) $86 \% \pm 31$ s.d. recovery $(n=7)$ of apo $\mathrm{B} 15$ in wheat-germ lysates with proteinase $\mathrm{K}$. In contrast, we find $0 \%(n=4)$ recovery of apo $\mathrm{B} 15$ or B17 in saponin-disrupted microsomes after proteinase $\mathrm{K}$ digestion. Although we routinely included the membrane stabilizer tetracaine ${ }^{13}$ in digestion mixtures, we cannot detect transmembrane domains when tetracaine is absent but $\mathrm{Ca}^{2+}$ is present (results not shown) ${ }^{1}$; in contrast, substantially reduced levels of putative intermediates have been observed with tetracaine present (S. L. Chuck and V. R. Lingappa, unpublished), which suggests that the data in ref. 1 may be a result of overdigestion.

We conclude that apo B is cotranslationally translocated into microsomes and binds to the inner leaflet of membrane. The binding of the amino terminus of apo $\mathrm{B}$ forms a focus for association of the remainder of the elongating protein with the membrane, circumventing the problems of size and hydrophobicity. It is probable that this amphipathic form of apo $B$ 
FIG. 1 SDS-PAGE showing expression of apo B7 and apo B9. a, Apo B9 was translated in the presence (tracks $1,2,3,6$ ) or absence $(4,5)$ of microsomes $(\mathrm{m})$. To samples 4 and 5 , microsomes were added post-translationally (pt). Samples were digested with trypsin (Trp) in the presence (track 6) or absence (tracks $2,3,4,5$ ) of detergent $(T x)$ or were undigested (track 1 ) Apo B9 is protected if cotranslationally imported into microsomes. Protected intermediates of synthesis (relative molecular masses $\left(M_{r}\right) 38,000$ and 40,000 (38K and 40K)) are apparent in some translations, but do not affect the interpretation of the experiment. The yield of apo B9 is stimulated by microsomes (tracks 1 and 4). When translation is carried out in the absence of microsomes (tracks 4,5 ) peptidyl tRNA is apparent at $\sim 25 \mathrm{~K}$. B9.CHO glycosylated apo B9. b. Apo B7 was translated in the presence (tracks 2,3) or absence $(1,4)$ of microsomes, with (track 3 ) or without (tracks $1,2,4$ ) $100 \mu \mathrm{M} \mathrm{N}$-acetyl-AsnTyrThrcarboxyamide (NYT) ${ }^{6}$. The peptide inhibited glycosylation of apo B7 to generate a protein species (B7) of faster migration than pre-apo $B 7$, indicating cleavage of the MetAla signal sequence. $\mathrm{B} 7 . \mathrm{CHO}$, glycosylated apo B7.

METHODS. To generate the apo B9 transcript, construct EB9 was linearized with Sall and transcribed with T7 RNA polymerase (Boehringer). To generate the apo B7 transcript, construct EB9 was linearized at the Stul $(1,199)$ site of the CDNA and transcribed. RNA was translated in unfractionated reticulocyte lysates (Amersham), with $\left[{ }^{35}\right.$ S $]$ methionine (Amersham) and, where indicated, in the presence of canine pancreatic microsomes (Promega). For protease digestion, translation mixtures were treated with $0.5 \mathrm{mg} \mathrm{ml}^{-1}$ tosyl amino phenyl ethyl chloromethyl ketone (TPCK) trypsin (Cooper Biomedical) for $90 \mathrm{~min}$ at $0^{\circ} \mathrm{C}$ in $20 \mathrm{mM}$ Tris- $\mathrm{HCl}, \mathrm{pH} 7.5$, and $2 \mathrm{mM}$ tetracaine$\mathrm{HCl}(\mathrm{Sigma})^{13}$. Where indicated, membranes were disrupted with $0.1 \%$ Triton $\mathrm{X}-100$ during digestion. Digestions were terminated with $6 \mathrm{mg} \mathrm{ml}^{-1}$ final concentration soybean trypsin inhibitor (Sigma). Proteins were resolved on $8 \rightarrow 15 \%$ gradient SDS-polyacrylamide gels ${ }^{14}$. Subcloning: We used a plasmid (from M. Howell and T. Hunt) containing nucleotides 259 to 837 of the $5^{\prime}$ UTR of EMCV with a novel Ncol site (underlined) created downstream of the first ATG (nucleotide 834) of the viral coding sequence: gattatATG GCCATGG. This encodes MetAla then the first Met and subsequent residues of any open reading frame cloned into the $\mathrm{Ncol}$ site. Apo B cDNA (refs 15, 16) was amplified by polymerase chain reaction (PCR) between nucleotides 128 and 400. A mismatched $5^{\prime}$ oligonucleotide introduced an $\mathrm{Ncol}$ site at the first Met in the apo B signal sequence. The sequence ${ }^{17}$ of this product $\mathrm{Ncol} \rightarrow$ Pstl (394) showed a single nucleotide difference from the published sequence predicting $\operatorname{Thr}(40) \rightarrow$ Ser. This was ligated to the Ncol site of the
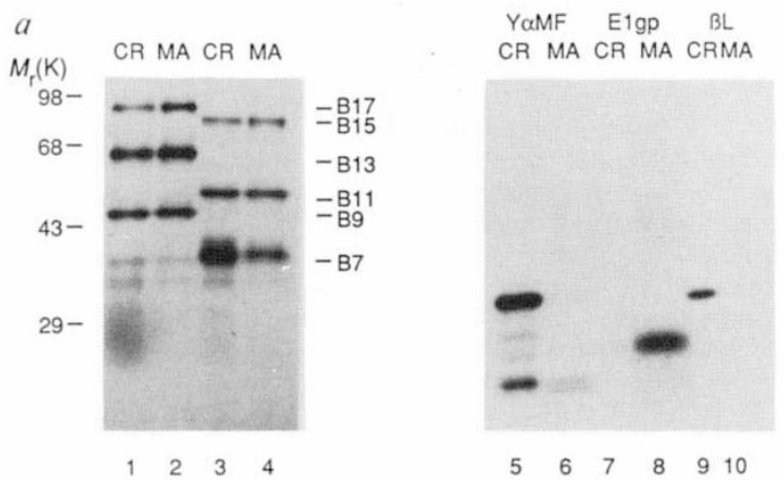

FIG. 2 Membrane of nascent apo B. a, Transcripts of apo B7 to B17 and of control proteins were translated in the presence of microsomes. Carbonate releasable (CR) and membrane associated (MA) proteins were resolved by SDS-PAGE. The tracks show: 1 and 2, mixed apo B9, B13, and B17; 3 and 4, mixed apo B7, B11 and B15; 5 and 6 , yeast $\alpha$-mating factor ( $\mathrm{Y} \alpha \mathrm{MF})$; 7 and $8 E_{1}$ glycoprotein (E1gp); 9 and $10, \beta$-lactamase $(\beta L)$. There is significant association of apo B9, 11, 13, 15 and 17 with the membranes, but apo $\mathrm{B} 7$ is mainly releasable with carbonate, $(\sim 80 \%)$. $b$, Apo B17 transcripts were translated in the presence of microsomes and were then either untreated (tracks 1,2) or treated with saponin for 0 min (tracks 3,4 ) or 90 min (tracks 5,6 ). Transcripts of $E_{1}$ glycoprotein (tracks 7,8 ), yeast $\alpha$-mating factor (tracks 9,10 ) and $\beta$-lactamase (tracks 11,12 ) were translated in the presence of microsomes and treated with saponin for $90 \mathrm{~min}$. Soluble (S) and membrane (M) fractions were separated and displayed by SDS-PAGE. Apo B17 is associated with the membrane fraction under conditions in which soluble proteins are released. Some apo B17 is present in the saponin-releasable fraction but migrates faster, and represents unprocessed pre-apo B17.

METHODS. To generate the apo B13 transcript construct EB17 was first

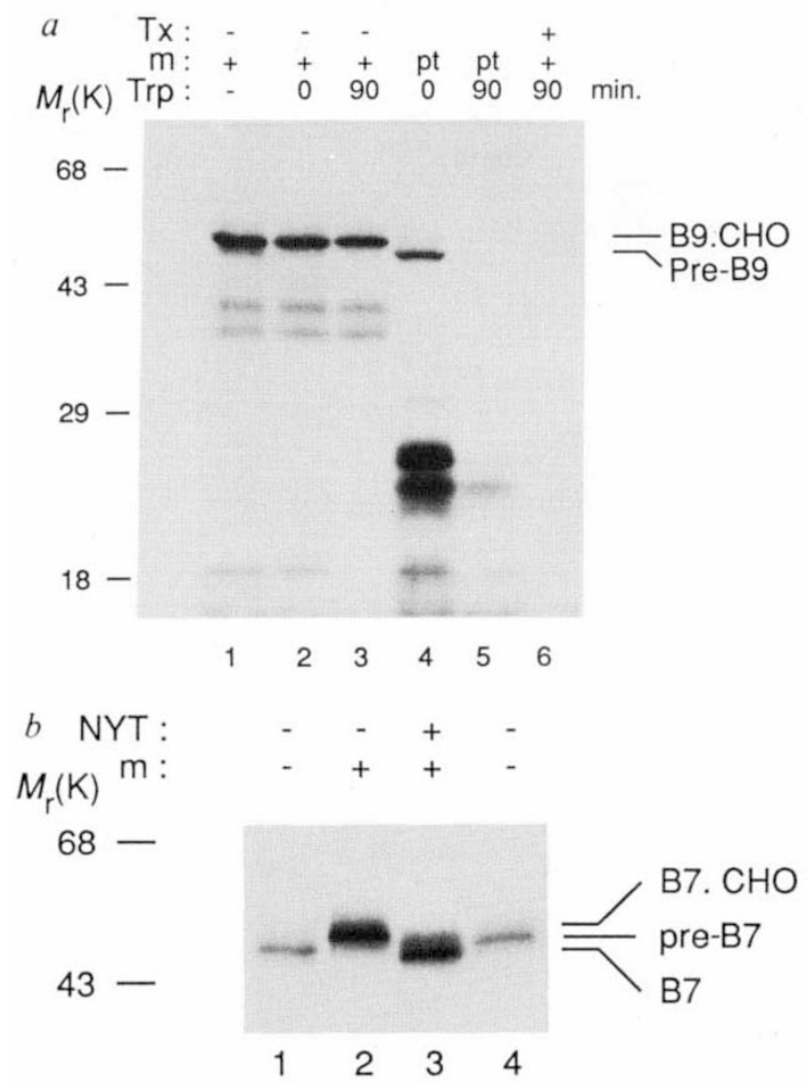

modified EMCV 5' UTR and extended with apo B CDNA to encode: MetAla-preapo B9 (Ile(402)SerGluLysSerTer) (plasmid EB9); MetAla-pre-apo B11 (Thr(476) IleSerLyslleTer) (plasmid EB11); MetAla-pre-apo B15(Ala(691)TyrArgTyrArgArg) (plasmid EB15); and MetAla-pre-apo B17 (Ile(782)LeuThrLeuAlaGlySerMetGluSerProTer) (plasmid EB17). 

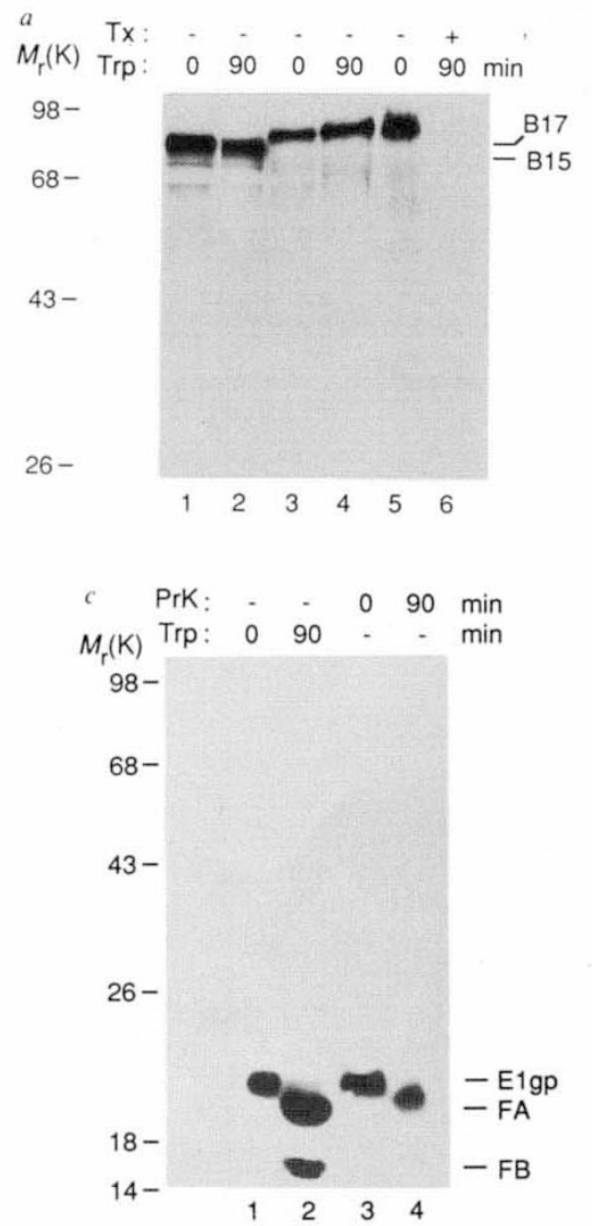

FIG. 3 Luminal disposition of apo B in microsomes. a, Apo B15 (tracks 1,2 ) or apo B17 (tracks $3,4,5,6$ ) transcripts were translated in reticulocyte lysates in the presence of microsomal membranes for 40 min (tracks 3,4 ) or $90 \mathrm{~min}$ (tracks 1,2,5,6) and digested with trypsin for $0 \mathrm{~min}$ or $90 \mathrm{~min}$. In tracks $6,0.1 \%$ Triton $\mathrm{X}-100$ (TX) was included during the digestion. $b$, Apo B17 was translated in the presence of microsomes and then aliquots were left undigested (tracks 1 and 4) or were digested for $60 \mathrm{~min}$ with proteinase $\mathrm{K}$ (PrK) (tracks 2,3 ) in the presence $(3,4)$ or absence $(1,2)$ of $0.05 \%$ saponin (Sa). Membranes were collected by ultracentrifugation. The results show that apo B17 is protected from proteinase $\mathrm{K}$ if cotranslationally translocated into microsomes, but not if the microsomes are disrupted with saponin during digestion. $C, E_{1}$ glycoprotein transcripts were translated in reticulocyte lysates in the presence of microsomal membranes and digested with trypsin (tracks 1,2 ) or proteinase $K$ (tracks 3,4 ) for 0 min (tracks 1,3) or $90 \mathrm{~min}$ (tracks 2, 4). $\mathrm{E}_{1}$ glycoprotein (E1gp) was cleaved from a protein of apparent $M_{\mathrm{r}} 23.5 \mathrm{~K}$ to a major product (FA) of $22 \mathrm{~K}$ and a minor product (FB) of $19.5 \mathrm{~K}$ (ref. 10), which migrates here at $<18 \mathrm{~K}$. The $22 \mathrm{~K}$ product is generated by cleavage of the cytoplasmic domain of E1gp. The smaller product is generated by cleavage of both the cytoplasmic and luminal domains ${ }^{10}$. $d$, Apo B15 transcripts were translated in wheat-germ lysate in the presence of microsomes for $60 \mathrm{~min}$, and then the membranes were

subsequently buds into the lumen, carrying phospholipid and neutral lipids, to form the nascent lipoprotein particle ${ }^{9}$.

\section{Received 8 April; accepted 16 August 1991}

1. Chuck, S. L., Yao, Z., Blackhart, B. D., McCarthy, B. J. \& Lingappa, V. R. Nature 346, 382-385(1990) 2. Davis, R. A., Thrift, R. N., Wu, C. C. \& Howell, K. E. J. biol, Chem. 265, 10005-10011 (1990).

3. Klausner, R. D. \& Sitia, R. Cell 62, 611-61, (1990)

4. Kaminski, A., Howell, M. T. \& Jackson, R. J. EMBO J. 9, 3753-3759 (1990).

5. Walter, P. \& Blobel, G. Meth. Enzym. 96, 84-94 (1983).

6. Kassenbrock, C. K., Garcia, P. D., Walter, P. \& Kelly, R. B. Nature 333, 90-93 (1988)

7. Fujiki, Y., Hubbard, A. L., Fowler, S. \& Lazarow, P. B. J. Cell Biol. 93, 97-102 (1982).

8. Howell, K. E. \& Palade, G. E. J. Cell Biol, 92, 822-832 (1982).

9. Bostrom, K. et al. J. biol. Chem. 263, 4432-4442 (1988).

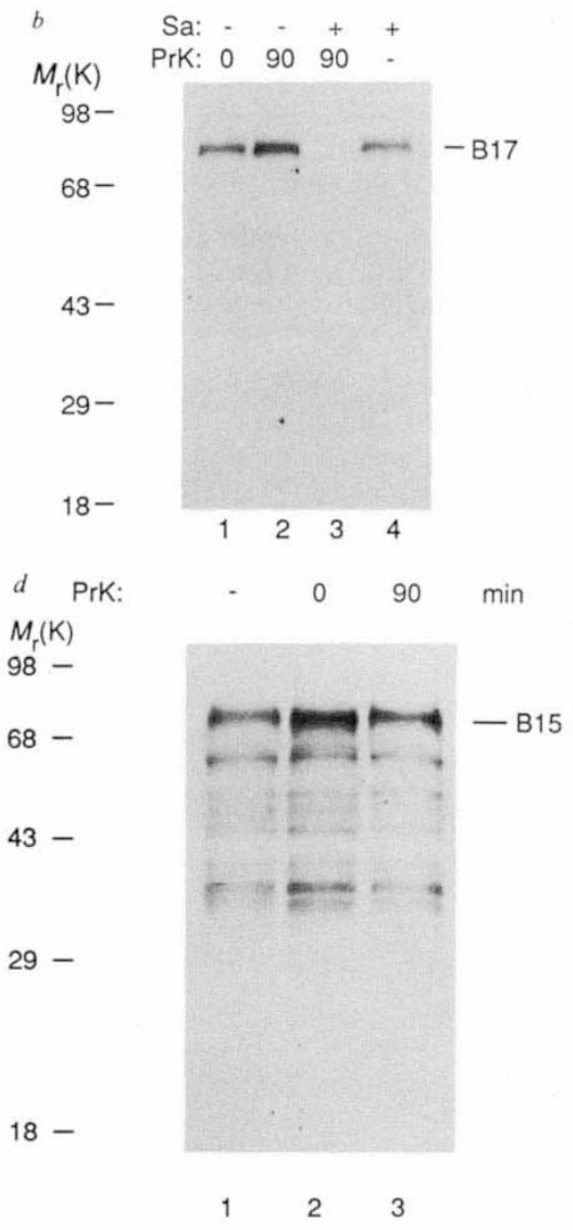

collected by centrifugation before (track 1 ) or after digestion with proteinase $\mathrm{K}$ for $0 \mathrm{~min}$ (track 2 ) or $90 \mathrm{~min}$ (track 3 ). Some partial synthesis products are present in all tracks but no new bands are generated by protease digestion.

METHODS. Apo B15 capped transcripts were prepared by linearizing construct GB15 with Sall and transcribing with $T 7$ polymerase in the presence of $0.5 \mathrm{mM}$ GTP with $5 \mathrm{mM} 7$-methyl GpppG (Pharmacia), and fractionated on a Sephadex-G25 spin column (Pharmacia). Fractionated wheat germ lysate (Amersham) was reconstituted to $120 \mathrm{mM} \mathrm{K}^{+}$, with a $1 \mathrm{mM}$ mixture of unlabelled amino acids excluding Met. Proteinase $K$ digests were diluted with 2 volumes of $250 \mathrm{mg} \mathrm{ml}^{-1}$ BSA in $0.15 \mathrm{M} \mathrm{NaCl}$ with $5 \mathrm{mM}$ PMSF. Membranes were collected in an airfuge and washed 3 times with $\mathrm{NaCl}$ solution before dissolving in SDS loading buffer plus $5 \mathrm{mM}$ PMSF for SDSPAGE. In some instances membranes were disrupted with $0.05 \%$ saponin before protease digestion. Proteins were resolved on $8-15 \%$ or, for $c$, on 7-17\% SDS-PAGE polyacrylamide gradient gels. Subcloning: The 50-nucleotide $5^{\prime}$ UTR of human $\beta$-globin containing the natural $N \mathrm{Col}$ site at the first ATG of the coding sequence ${ }^{20}$ was synthesized as oligonucleotides with a $5^{\prime}$ Sstl site and a $3^{\prime}$ Sstll site to enable it to be cloned into the polylinker of plasmid pKS. Pre-apo B15 was constructed by ligation of $\mathrm{Ncol} \rightarrow$ Hind III $(2,279)$ fragments of cDNA to generate plasmid GB15.
10. Rottier, P., Brandenberg, D., Armstrong, J., van der Zeijst, B. \& Warren, G. Proc. natn. Acad. Sci. U.S.A. 81, 1421-1425 (1984).

11. Yost, C. S., Lopez, C. D., Prusiner, S. B., Myers, R. M. \& Lingappa, V. R. Nature 343, 669-672 (1990). 12. Spiess, M., Handschin, C. \& Baker, K. P. J. biol. Chem. 264, 19117-19124 (1989).

13. Scheele, G. Meth. Enzym. 96, 94-111 (1983).

14. Laemmli, U. K. Nature 227, 680-685 (1970).

15. Knott, T. J. et al. Nature 323, 734-738 (1986)

16. Knott, T. J. et al. Nucleic Acids Res. 14, 7501-7503 (1986)

17. Sanger, F., Nicklen, S. \& Coulson, A. R. Proc. natn. Acad. Sci. U.S.A. 74, 5463-5467 (1977)

18. Rogers, G., Gruenebaum, J. \& Boime, I. J. biol. Chem. 257, 4179-4186 (1982).

19. Armstrong, J., Niemann, H., Smeekens, S., Rottier, P. \& Warren, G. Nature 308, 751-752 (1984) 20. Lawn, R. M., Efstratiadis, A., O'Connell, C. \& Maniatis, T. Cell 21, 647-651 (1980).

ACKNOWLEDGEMENTS. We thank T. Hunt (University of Cambridge) for advice on in vitro transtation, J. Armstrong and G. Warren (ICRF, London) for the CDNA of the $E_{1}$ glycoprotein. P. Hodges for his interest, T. Knott for synthesis and oligonucleotides, P. Byfield for protein sequencing, S. Pemberton for peptide synthesis, and I. Haywood for secretarial assistance. 